\author{
НАТАЛИЯ КИРИЛЛОВА
}

\title{
Некоторые проблемы защиты права собственности при применении мер уголовно-процессуального принуждения
}

\section{1. Ограничение права собственности путем применения мер уголовно-процессуального принуждения}

\section{1 Ограничение права собственности путем наложения ареста на имущество}

Неприкосновенность собственности имеет основополагающее значение для правопорядка. От того, насколько реальны гарантии защиты собственности от любых неправомерных посягательств, зависит стабильное функционирование не только гражданского оборота, но и всей экономики, а стало быть, устойчивое развитие общества. Признание, соблюдение и защита права частной собственности, относящегося к основным правам, неотчуждаемым и принадлежащим человеку от рождения, составляет обязанность государства.

В процессе осуществления уголовного судопроизводства право собственности может быть ограничено. Это касается, прежде всего, подозреваемых и обвиняемых. Данное ограничение имеет целью защиту права собственности и иных имущественных прав, потерпевших от совершения преступления. В процессе уголовного судопроизводства должен быть соблюден баланс интересов участников процесса, основанный на правильном применении норм, ограничивающих право собственности.

Потерпевший осуществляет защиту права собственности путем предъявления гражданского иска в уголовном процессе. Однако само по себе предъявление иска не гарантирует восстановления нарушенного права. Как известно, право собственности регламентируется преимущественно нормами гражданского права, которые применяются в гражданском или арбитражном судопроизводстве. Вместе с тем вопросы собственности затрагиваются и в других отраслях права, в том числе в уголовном праве, предусматривающем штрафы, конфискацию имущества, а также в уголовно-процессуальном праве, регулирующем применение норм уголовного права. В уголовном процессе России существует институт гражданского иска, так называемый соединенный 
288 | Adam Mickiewicz University Law Review

процесс, при котором в рамках уголовного дела одновременно рассматривается гражданско-правовой вопрос о возмещении вреда, причиненного преступлением. Защиту указанного права обеспечивает применение некоторых мер уголовно-процессуального принуждения. Законность, обоснованность, своевременность применения этих мер способствует восстановлению нарушенного права.

Наиболее актуальной мерой процессуального принуждения, позволяющей защитить право собственности, является наложение ареста на имущество. Нарушения уголовно-процессуального закона при применении этой меры может повредить как потерпевшему (например, несвоевременность наложения ареста на имущество), так и обвиняемому и даже иным лицам (когда, например, арест наложен на имущество, не принадлежащее обвиняемому или на имущество вообще не подлежащее аресту).

Наложение ареста на имущество - это превентивно-обеспечительная мера процессуального принуждения, содержание которой состоит в ограничениях права собственности (иного вещного права) для предупреждения ее сокрытия или отчуждения с целью обеспечить исполнение приговора в части имущественных взысканий.

К имущественным взысканиям относятся: 1) удовлетворение гражданского иска, заявленного в уголовном деле [ст. ст. 44, 309 УПК РФ (Уголовно-процессуальный кодекс Российской Федерации)]; 2) применение иной меры уголовно-правового характера в виде конфискации имущества (ст. 104.1 УК РФ - Уголовный кодекс Российской Федерации); 3) другие имущественные взыскания с обвиняемого или гражданского ответчика, связанные с данным уголовным делом (взыскание процессуальных издержек с осужденного - ч. 1 ст. 132 УПК РФ, наложение денежного взыскания на законных представителей несовершеннолетнего обвиняемого или подозреваемого за неисполнение обязанностей по присмотру за ними - ст. 117 УПК РФ).

\section{2 Условия и порядок наложения ареста на имущество}

Условия применения института наложения ареста на имущество в зависимости от их правовой природы можно разделить на две группы: условия, имеющие материальноправовую природу, и процессуально-правовые условия. Процессуально-правовыми условиями являются обстоятельства, от которых зависит возможность применения данной меры: 1) наличие возбужденного уголовного дела; 2) наличие надлежащего должностного лица, правомочного применить меру принуждения; 3) наличие лица, в отношении которого может применяться мера принуждения; 4) наличие обоснованного подозрения или обвинения в отношении конкретного лица.

Наложение ареста на имущество допускается только при наличии одного или нескольких специальных условий. Во-первых, когда установлены: причинение имущественного или морального вреда преступлением; заявлен гражданский иск (ст. 44 УПК РФ). При отсутствии гражданского иска его обеспечение не должно применяться, так как право предъявления иска диспозитивно. Во-вторых, установлены обстоятельства, 
подтверждающие, что имущество, подлежащее конфискации в соответствии со статьей 104.1 УК РФ, получено в результате совершения преступления или является доходами от этой деятельности, либо использовалось или предназначалось для использования в качестве орудия преступления, для финансирования терроризма, организованной группы, незаконного вооруженного формирования, преступного сообщества преступной организации (п. 8 ч. 1 ст. 73; п. 3.1 ст. 82 УПК РФ). В-третьих, установлен размер понесенных судебных издержек, которые реально могут быть возложены на обвиняемого.

Основанием наложения ареста на имущество является обоснованное предположение, что подлежащее взысканию имущество может быть сокрыто или отчуждено.

Арест накладывается на имущество, принадлежащее подозреваемому, обвиняемому или лицам, несущим материальную ответственность по закону за их действия. По гражданскому иску соучастники преступления несут солидарную ответственность, поэтому в обеспечение иска их имущество может быть арестовано в любых пропорциях, но общая его стоимость не должна превышать грозящего имущественного взыскания.

Наложение ареста на имущество производится только по решению суда (п. 9 ч. 2 ст. 29 УПК РФ), так как в соответствии с частью 3 ст. 35 Конституции Российской Федерации никто не может быть лишен своего имущества иначе как по решению суда.

В стадии предварительного расследования суд в порядке, предусмотренном ст. 165 УПК РФ, выносит постановление о наложении ареста на имущество по результатам рассмотрения ходатайства следователя или дознавателя, которые обязаны исполнить данное постановление. В неотложных случаях имущество может быть арестовано и без судебного разрешения. В этом случае следователь или дознаватель в течение 24 часов с момента начала производства процессуального действия уведомляет судью и прокурора о его производстве. К уведомлению прилагаются копии постановления о производстве следственного действия и протокола следственного действия для проверки законности принятого следователем или дознавателем решения. Получив указанное уведомление, судья в срок, предусмотренный часть 2 ст. 165 УПК РФ, проверяет законность произведенного следственного действия и выносит постановление о его законности или незаконности.

В судебных стадиях уголовного процесса судья, принявший дело к производству, выносит постановление о наложении ареста на имущество по ходатайству стороны обвинения (п. 5 ст. 228; ст. 230 УПК РФ). Представляется, что при наличии указанных выше оснований и условий судья должен иметь право наложить арест на имущество и по своей инициативе при отсутствии возражений со стороны обвинения. Постановление о наложении ареста на имущество, вынесенное в судебном производстве, исполняется судебным приставом-исполнителем.

Копия постановления вручается гражданскому истцу по его ходатайству. Для обжалования данного постановления с ним должен быть ознакомлен и гражданский ответ- 
290 | Adam Mickiewicz University Law Review

чик. Очень важна возможность обжалования таких решений в апелляционном и кассационном порядке.

На стадии предварительного расследования решение и действия по наложению ареста на имущество могут быть обжалованы заинтересованными участниками процесса в апелляционном и кассационном порядке. Законные владельцы имущества вправе подать иск об исключении имущества из описи (освобождения от ареста) в порядке гражданского судопроизводства. Удовлетворение иска влечет отмену ареста конкретного имущества, а решение гражданского суда о принадлежности имущества имеет преюдициальную силу. Иск об освобождении имущества от ареста может быть подан в течение срока исковой давности, в том числе после исполнения имущественного взыскания.

Содержание меры принуждения в виде наложения ареста на имущество состоит в ограничении прав собственности (хозяйственного ведения или оперативного управления). При этом всегда ограничивается право распоряжения имуществом (запрет отчуждения).

Если ограничения прав по распоряжению и пользованию не могут обеспечить цели наложения ареста на имущество, то ограничивается и право владения - имущество изымается и передается на хранение другим лицам. Конкретные ограничения должны быть указаны в постановлении суда.

По общему правилу до вынесения постановления о наложении ареста на имущество должны быть установлены: индивидуально-определенные признаки, стоимость и местонахождение имущества, подлежащего аресту; принадлежность этого имущества обвиняемому (подозреваемому) или другому гражданскому ответчику.

Закон не запрещает налагать арест на имущество, указывая в постановлении лишь его принадлежность и стоимость. После вынесения судом постановления следователь, дознаватель или судебный пристав-исполнитель должны установить и разыскать конкретное имущество, подлежащее аресту.

Подлежащее аресту имущество разыскивается путем производства следственных действий, и проведения оперативно-розыскных мероприятий, предусмотренных ст. 6 Ф3 (Федеральный закон) Об оперативно-розыскной деятельности от 12 августа 1995 г. N 144-Ф3. При наложении ареста на принадлежащие подозреваемому, обвиняемому денежные средства и иные ценности, находящиеся на счете, во вкладе или на хранении в банках и иных кредитных организациях, операции по данному счету прекращаются полностью или частично в пределах денежных средств и иных ценностей, на которые наложен арест. Руководители банков и иных кредитных организаций обязаны предоставить информацию об этих денежных средствах и иных ценностях по запросу суда, а также следователя или дознавателя на основании судебного решения.

Часть 3 ст. 115 УПК РФ предусматривает возможность ареста имущества, находящегося у других лиц, то есть не у обвиняемого или подозреваемого. Арест может быть 
наложен на имущество, находящееся у других лиц, если есть основания полагать, что оно использовалось или предназначалось для использования этими самыми лицами в качестве орудия преступления либо для финансирования терроризма, организованной группы, незаконного вооруженного формирования, преступного сообщества или преступной организации. Такое имущество, переданное осужденным другому лицу или организации, подлежит конфискации, если лицо, принявшее имущество, знало или должно было знать, что оно получено в результате преступных действий. В этой ситуации под другими лицами понимаются лица, фактически заподозренные в совершении преступления, т.е. орган, осуществляющий уголовное преследование, располагает достаточными данными о том, что они использовали имущество в качестве орудия преступления, финансировали терроризм и т.д.

При исполнении ареста подлежат изъятию (копированию) правоустанавливающие документы, подтверждающие право собственности. Тем самым исключается неправомерный арест чужого имущества, а также опровергаются возможные ложные заявления (в том числе исковые) о том, что арестованное имущество принадлежит другим лицам.

Наложение ареста отменяется при прекращении уголовного дела или уголовного преследования конкретного лица; постановлении оправдательного приговора; отказе истца от гражданского иска; добровольном возмещении ущерба; отказе судом в удовлетворении гражданского иска; оставлении иска без рассмотрения; недоказанности того, что имущество нажито преступным путем; доказанности, что имущество принадлежит не гражданскому ответчику. При приостановлении дела, прекращении производства по гражданскому иску, оставлении его без рассмотрения уголовно-процессуальная мера принуждения в виде наложения ареста на имущества может быть заменена аналогичной гражданско-процессуальной мерой в порядке, предусмотренном гражданским процессуальным законодательством (глава 13 ГПК РФ). Для этого по ходатайству гражданского истца уголовно-процессуальный арест имущества целесообразно продлить на срок, достаточный для предъявления иска в порядке гражданского судопроизводства.

Для отмены наложения ареста на имущество при предварительном расследовании достаточно постановления следователя или дознавателя, в производстве которого находится уголовное дело, когда основания для применения этой меры отпали.

Законодательство некоторых государств постсоветского пространства предписывает отменить арест имущества в случае, когда он был наложен незаконно. Полагаем, что это самостоятельное обстоятельство, при наличии которого необходимо отменить наложение ареста на имущество, тем самым защитить права лиц, имущество которых было незаконно подвергнуто аресту. Например, когда судья в соответствии с ч. 5 ст. 165 УПК России в ходе проверки поступившего уведомления о производстве наложения ареста на имущество, придет к выводу о незаконных и необоснованных действиях следователя. 
292 | Adam Mickiewicz University Law Review

Таким образом, используемая в ч. 9 ст. 115 УПК РФ конструкция института отмены наложения ареста на имущество не является универсальной и всеобъемлющей. Из законодательного регулирования выпадают ситуации, связанные с устранением условий применения рассматриваемой меры. Поэтому некоторые практические работники предлагают внести изменения, определив данную норму следующим образом:

Наложение ареста на имущество отменяется на основании постановления, определения лица или органа, в производстве которого находится уголовное дело, в следующих случаях: в применении данной меры отпадает необходимость; если арест был наложен незаконно, в том числе без достаточных для этого оснований или в порядке, не соответствующем закону롤.

В некоторых государствах, например в Германии, в исключительных случаях наложенный арест может быть отменен по ходатайству обвиняемого, если последний нуждается в арестованном для оплаты своей защиты, своего содержания или содержания своей семьи ${ }^{2}$.

Было бы целесообразно предусмотреть аналогичную процессуальную гарантию и в России.

\section{2. Роль конституционного правосудия в защите права собственности}

Конституционный Суд РФ 31 января 2011 года вынес Постановление N 1-П по делу о проверке конституционности положений ст. 115, 208 УПК РФ и ст. 126 Федерального закона О несостоятельности (банкротстве) которое продемонстрировало, что Конституционный Суд РФ осуществляет защиту права собственности и противодействует его неоправданному ограничению. Имущество одного из заявителей - ЗАО (Закрытое акционерное общество) Недвижимость- $M$ - было арестовано в уголовном деле по гражданскому иску потерпевшего - ОАО (Открытое акционерное общество) Банк Левобережный, который требовал обратить на это имущество взыскание по договору залога. Залог же обеспечивал выплату кредита, похищенного неустановленными лицами. При этом владелец арестованного имущества (ЗАО Недвижимость-M) статуса гражданского ответчика в уголовном деле не имел.

1 И.Б. Тутынин, Основания и условия отмены наложения ареста на имущество в стадии предварительного расследования, Исполнительное право 1/ 2009, С. 2-4.

2 А.Г. Волеводз, Правовое регулирование новых направлений международного сотрудничества в сфере уголовного прочесса, Москва 2002, С. 178. 
Кроме того, по данному делу было рассмотрено заявление ООО Соломатинское хлебоприемное предприятие, имущество которого также было арестовано по уголовному делу в целях обеспечения исполнения приговора в части гражданских исков потерпевших, которые являлись участниками конкурсного производства в связи с признанием данного юридического лица банкротом. Органы предварительного следствия и суды, осуществляющие производство по уголовному делу, отказались принимать во внимание п. 1 ст. 126 Федерального закона О несостоятельности (банкротстве). Согласно данной норме на основании решения арбитражного суда о признании должника банкротом и об открытии конкурсного производства, ранее наложенные аресты на имущество должника снимаются, и не допускается наложение новых арестов и иных ограничений распоряжения его имуществом.

Для разрешения поставленных вопросов Конституционный Суд РФ, опираясь на свои предыдущие решения, сформулировал новое конституционно-правовое положение о разграничении видов судопроизводств. Исходя из требований ст. ст. $46-53,118$, 120, 123 и 125 - 128 Конституции РФ, федеральный законодатель закрепляет способы и процедуры судебной защиты по отношению к отдельным видам судопроизводства и категориям дел. При этом учитываются особенности соответствующих материальных правоотношений, характер рассматриваемых дел, существо и значимость вводимых санкций, а также правовые последствия их применения. Этим не исключается возможность установления в рамках того или иного вида судопроизводства особых процедур, которые должны обеспечить эффективность судебной защиты прав и свобод человека и гражданина по определенным категориям дел. Однако, вводя такие процедуры, законодатель обязан соблюдать принципы, лежащие в основе организации и осуществления правосудия, разграничения судебной юрисдикции, обеспечения прав и свобод человека и гражданина. Не вправе отступать от этих требований и правоприменитель при уяснении смысла и толковании норм применяемого закона.

Данное конституционно-правовое положение было использовано Конституционным Судом РФ для анализа института гражданского иска в уголовном деле. Предусматривая в уголовном судопроизводстве особую процедуру - институт гражданского иска, федеральный законодатель преследовал цель обеспечить более эффективную защиту субъективных гражданских прав и скорейший доступ к правосудию. Вместе с тем гражданскоправовые требования о возмещении имущественного вреда, причиненного преступлением (вне зависимости от того, подлежат они рассмотрению в гражданском или уголовном судопроизводстве), разрешаются в соответствии с нормами гражданского законодательства. Потому суды общей юрисдикции при анализе в уголовном судопроизводстве вопросов, касающихся отношений собственности, не должны, по мнению Конституционного Суда РФ, допускать подмены частноправовых механизмов разрешения споров о собственности уголовно-процессуальными средствами, направленными на достижение публично-правовых целей уголовного судопроизводства. В производстве по гражданскому 
294 | Adam Mickiewicz University Law Review

иску в уголовном деле, включая принятие обеспечительных мер в виде наложения ареста на имущество, не должны создаваться препятствия для правильного и своевременного осуществления правосудия по уголовным делам, равно как не должно чрезмерно ограничиваться право собственности лица, на имущество которого наложен арест.

На этой основе Конституционный Суд РФ пришел к следующим выводам:

- применение в отношении лиц, на которых законом возложена материальная ответственность за действия подозреваемых или обвиняемых, меры процессуального принуждения в виде наложения ареста на имущество предполагает установление личности подозреваемого, обвиняемого. Практически это означает запрет применения по нераскрытым преступлениям ареста имущества лиц, не являющихся подозреваемыми и обвиняемыми, в целях обеспечения гражданского иска;

- наложение в порядке обеспечения исполнения приговора в части гражданского иска ареста на имущество лица, несущего по закону материальную ответственность за чужие действия перед гражданским истцом по уголовному делу, предполагает предварительное привлечение владельца имущества в качестве гражданского ответчика. Такое толкование закона, с одной стороны, наделяет собственника комплексом прав, закрепленных ч. 2 ст. 54 УПК РФ для гражданского ответчика, а с другой - позволяет проверить наличие оснований для вынесения данного решения;

- положение ч. 1 ст. 115 УПК РФ (предполагающее в целях обеспечения исполнения приговора в части гражданского иска наложение ареста на имущество лиц, несущих по закону материальную ответственность за действия подозреваемого или обвиняемого) означает, что арест может быть наложен на имущество лишь того лица, которое по закону несет за действия подозреваемого или обвиняемого материальную внедоговорную ответственность, вытекающую из причинения вреда.

Таким образом, в уголовном деле возможно рассмотрение гражданских исков к лицам, которые несут ответственность перед истцом исключительно в соответствии с гражданским кодексом. Соответственно, запрещается привлекать в качестве гражданских ответчиков, налагать арест на имущество лиц, которые несут ответственность перед истцом не по закону, а по договору, в том числе залога, поручительства, банковской гарантии и т.д.. Вопрос о взыскании ущерба с данных лиц по договорам подлежит разрешению в порядке гражданского (арбитражного) судопроизводства, так как выяснение действительности подобных договоров, условий их заключения и фактического выполнения обязательств сторонами не связано непосредственно с целями осуществления правосудия по уголовным делам и относится к сфере гражданского судопроизводства ${ }^{3}$. В рассматриваемом Постановлении. Конституционного Суда РФ указано, что ч. 3 ст. 115 УПК РФ во взаимосвязи с абз. 9 п. 1 ст. 126 Федерального закона О несостоятельности (банкротстве) не предполагает наложение ареста на иму-

3 К. Калиновский, Дело по аресту имущества [online]. Международная ассоциация содействия правосудию [Доступ: 2013-10-08]. Доступны на: <http://www.iuaj.net/node/749>. 
щество должника, находящегося в процедуре конкурсного производства, либо сохранение ранее наложенного в рамках уголовного судопроизводства ареста на имущество должника после введения данной процедуры для обеспечения исполнения приговора в части гражданского иска в отношении отдельных лиц, являющихся конкурсными кредиторами. Этот вывод основан на том, что специальные нормы гражданского законодательства о банкротстве, устанавливающие особый режим имущественных требований к должнику и обеспечивающие принцип равенства кредиторов, должны пользоваться приоритетом перед общими правилами производства по гражданскому иску в уголовном процессе. Иное вело бы к созданию необоснованных преимуществ для кредиторов, заявивших гражданский иск в уголовном деле, перед другими кредиторами, не заявившими такого иска.

В данном судебном заседании Конституционный Суд РФ проанализировал вопрос о сохранении ареста имущества после приостановления производства по уголовному делу.

Поводом для этого послужила ситуация с арестом недвижимого имущества, принадлежащего Л.И. Костаревой, которой было запрещено не только распоряжаться им, но и пользоваться - сдавать в аренду. По версии следственных органов, данное имущество фактически было приобретено на средства, добытые преступным путем сыном заявительницы, и доходы от аренды этого имущества предназначались для финансирования преступной деятельности.

Уголовное дело было приостановлено на основании п. 2 ч. 1 ст. 208 УПК РФ в связи с тем, что подозреваемые скрылись и находятся в международном розыске. Как утверждала заявительница, арест на имущество в виде запрета им пользоваться, не освобождая ее от обязанности нести расходы по содержанию и эксплуатации принадлежащих ей офисных помещений, причиняет ей ежемесячные убытки в размере от 60 тыс. рублей до 150 тыс. рублей. Кроме того, он фактически влечет за собой принудительное банкротство с последующим отчуждением ее имущества.

Конституционный Суд РФ признал ч. 9 ст. 115 УПК РФ во взаимосвязи с ч. 3 той же статьи и п. 2 ч. 1 ст. 208 УПК РФ не соответствующими Конституции РФ в той мере, в какой они не предусматривают эффективных средств защиты законных интересов собственника имущества, на которое наложен арест для обеспечения исполнения приговора в части гражданского иска, в случаях приостановления предварительного следствия по уголовному делу в связи с тем, что подозреваемый, обвиняемый скрылся от следствия. При этом суд исходил из следующего. В существующей системе правового регулирования допускается сохранение действия меры принуждения в виде ареста имущества на все время приостановления предварительного следствия, то есть до истечения сроков давности уголовного преследования. Это означает, что при неустановлении местонахождения подозреваемого или обвиняемого, скрывшегося от следствия, арест имущества, находящегося у лиц, которые сами подозреваемыми или обвиня- 
296 | Adam Mickiewicz University Law Review

емыми по уголовному делу не являются, перестает быть временной мерой, которая применяется в рамках закрепленных в законе сроков. Подобный арест практически превращается для названных лиц в неопределенное по срокам ограничение права собственности. При этом собственнику не обеспечивается возможность воспользоваться эффективными средствами правовой защиты, с тем, чтобы понесенные им убытки не превышали действительно неизбежных, а сами ограничения не ставили под угрозу существо данных прав. Причем в законодательстве не урегулировано не только предотвращение убытков собственника в виде отмены запрета пользования арестованным имуществом в случае приостановления дела, но даже возмещение таких убытков в будущем, если дело завершится оправдательным приговором. Расходы собственника по содержанию арестованного имущества и неполученные доходы от его возможного использования не отнесены законом к процессуальным издержкам (ст. ст. 131 - 132 УПК РФ) и не подлежат возмещению в порядке реабилитации (ч. 3 и 5 ст. 133 УПК РФ). Законность ареста имущества исключает и возмещение вреда по ст. 1070 ГК РФ (Гражданский кодекс Российской Федерации) в гражданском судопроизводстве.

Кроме того, сохранение ареста на имущество в случаях приостановления предварительного следствия на неопределенный срок при отсутствии эффективного механизма защиты прав собственника по владению, пользованию и распоряжению этим имуществом по своему содержанию сопоставимо с конфискацией имущества, применяемой по приговору суда. В результате нарушается и принцип презумпции невиновности, на основании которого до вступления в законную силу обвинительного приговора на обвиняемого, а тем более на третьих лиц не могут быть наложены ограничения, сравнимые по степени тяжести с уголовно-правовыми мерами принуждения. Признавая перечисленные нормы неконституционными, КС РФ предписал федеральному законодателю внести в УПК РФ необходимые изменения, чтобы обеспечить эффективную защиту права собственности лицам, на чье имущество в рамках производства по уголовному делу, предварительное расследование по которому приостановлено, наложен арест для обеспечения исполнения приговора в части гражданского иска. Перед законодателем стоит и более общая проблема, поскольку УПК РФ не регламентирует вопрос о применении по приостановленному делу не только ареста имущества, но и других длящихся мер процессуального принуждения: подписки о невыезде, залога, домашнего ареста, отстранения от должности, удержания изъятых вещественных доказательств. Неограниченное по времени действие названных мер также не согласуется с выработанной Конституционным Судом РФ правовой позицией. До решения описанной проблемы законодателем в Постановлении от 31.01.2011 N 1-П на основе принципа прямого действия Конституции РФ сформулированы рекомендации для правоприменителя. Следственным органам, до приостановления предварительного следствия, необходимо принять все возможные меры к доказыванию виновности причастных к преступлению лиц и обстоятельств, подтверждающих преступное проис- 
хождение или использование арестованного имущества. Если будет установлена осведомленность собственника арестованного имущества об этих обстоятельствах, то он сам подлежит уголовному преследованию, а имущество - хранению в качестве вещественного доказательства. Если же причастность такого лица к преступлению не установлена, в случае приостановления предварительного следствия по уголовному делу требуется рассмотрение вопроса об отмене наложения ареста или изменении содержания данной меры принуждения. В частности, при надлежащем контроле за движением полученных денежных средств запрет пользования имуществом может быть отменен ${ }^{4}$. В настоящее время законодатель не изменил действующее законодательство, однако правоприменители используют в своей деятельности рассмотренное Постановление Конституционного Суда РФ, обеспечивая защиту права собственности.

\section{Биографическая аннотация:}

Наталия Кириллова - профессор кафедры уголовного процесса и криминалистики, юридического факультета Санкт-Петербургского государственного университета, доктор юридических наук. Сфера научных интересов: уголовный процесс, криминалистика, прокурорский надзор.

\section{SUMMARY}

Selected issues of the property right protection in the scope of criminal procedure compulsions

The aim of the study is to evaluate the relation between right to property and the criminal procedure compulsions. The author presents the selected issues of the property right protection law system in the context of the criminal proceeding.

KEYWORDS: property right protection, civil law, criminal procedure

4 Вестник Конституционного Суда РФ 2/2011. 
